\title{
Oncologic outcomes of nephron-sparing surgery in patients with T1 multifocal renal cell carcinoma
}

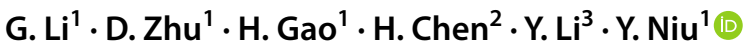

Received: 17 July 2018 / Accepted: 9 November 2018 / Published online: 15 November 2018

(c) The Author(s) 2018

\begin{abstract}
Objective This study is performed to explore the pathological characteristics and oncologic outcomes of T1 multifocal renal cell carcinoma (RCC).

Methods The clinical data of 600 patients (442 males and 158 females) between the age of 29 and 73 years, diagnosed with T1 RCC were collected from three hospitals in China, out of which 421 cases had undergone nephron-sparing surgery (NSS) and 179 cases had undergone radical nephrectomy (RN) between December 2010 and January 2015.

Results Tumor was identified with multifocality in 32 patients (5.33\%), out of which 21 were set to receive NSS, and 11 to receive RN, respectively; 21 cases of clear cell tumor, 8 cases of papillary tumor, 1 case of chromophobe tumor and 2 cases of Xp.11.2 translocation RCC. Among 568 cases of monofocal tumors, 400 patients underwent NSS, and the remaining 168 patients underwent RN, respectively. After a median follow-up of 5 years, 13 patients were found with recurrent tumors out of those who had undergone NSS, 11 with monofocal tumors and 2 with multifocal tumors containing satellite tumor nodules $(p=0.13)$. Out of the 32 individuals with multifocal RCC, 4 cases were reported to have died of cancer, 2 of NSS and 2 of RN. From these findings, the cancer-specific survival for NSS and RN was estimated to be $90.48 \%$ and $81.82 \%$, respectively $(p=0.48)$.

Conclusion The findings from the study suggested that there were pathological differences in multifocal renal tumors, and that papillary carcinoma may be more common than clear cell carcinoma. The recurrence rate and survival rate of multifocal RCC were similar to monofocal tumors. Tumor recurrence may be related to satellite tumor nodules, which can only be detected once surgery is performed.
\end{abstract}

Keywords Renal cell carcinoma $\cdot$ Multifocality $\cdot$ Nephron-sparing surgery $\cdot$ T1 stage $\cdot$ Pathology

$\begin{array}{ll}\text { Abbreviations } \\ \text { NSS } & \text { Nephron-sparing surgery } \\ \text { RN } & \text { Radical nephrectomy } \\ \text { RCC } & \text { Renal cell carcinoma } \\ \text { US } & \text { Ultrasound }\end{array}$

G. Li, D. Zhu and H. Gao are Co-first authors.

Y. Niu

urologist1985@sina.com

1 Department of Urology, Tianjin Institute of Urology, The Second Hospital of Tianjin Medical University, Tianjin Medical University, Tianjin 300211, China

2 The Second People's Hospital of Lianyungang, Lian Yungang City 222000, Jiangsu Province, China

3 Department of Pathology, The People's Hospital of Liao Cheng, Liao Cheng City 252000, Shandong Province, China
CT Computed tomography

PSMs Positive surgical margins

\section{Introduction}

Renal cell carcinoma (RCC) accounts for $2-3 \%$ of all human cancers and has an annual increase rate of approximately $2 \%$ globally [1]. Following the wide-range use of ultrasound (US) and computed tomography (CT) that aid the diagnosis of RCC, there has been a rapid increase in the number of RCC cases, especially for the T1 renal tumor [2]. Most RCCs involve solitary renal tumors, and multifocal RCC is estimated to occur in 5-25\% of the patients who undergo surgery due to renal malignancies [3-7]. The most effective and widely used treatment for T1a renal tumors is nephronsparing surgery (NSS), which provides long-term oncologic outcomes similar with radical nephrectomy $(\mathrm{RN})$ as well as 
a lower risk of renal insufficiency to avoid dialysis [8]. The substitution of RN with NSS for T1 RCC remains controversial at present due to the local recurrence and multicentricity associated with it. In this study, we aimed to investigate the pathological characteristics of T1 multifocal RCC, including tumor size, number, histological pattern, and satellite tumor nodules, in addition to prognosis of T1 multifocal RCC.

\section{Materials and methods}

\section{Patients}

After obtaining approval from hospital review boards, this study was performed in three hospitals in China. We retrospectively reviewed the medical data of patients with $\mathrm{T} 1$ RCC who had undergone NSS or RN in these three institutes from December 2010 to January 2015. According to the function of ipsilateral or contralateral kidney, tumor location and the requirements of patients, the majority of cases received NSS, and the minority of patients received RN, because they had such ipsilateral renal disorders as calculus, poor tumor location or the strong will of patients. Each patient was preoperatively evaluated with US and CT. The inclusion criteria were as follows: the patients were diagnosed with T1 RCC and preoperative images and postoperative pathological findings confirmed the presence of multifocal RCC. The patients with synchronous bilateral tumors, or with a solitary kidney were excluded, along with patients with familial or hereditary history of renal cancers.

\section{Clinicopathological assessment}

Following the surgery, surgical specimens were fixed in formalin, and reviewed by the 2 genitourinary pathologists. The RCC specimens were routinely sectioned at approximately $3 \mathrm{~mm}$ intervals and stained with hematoxylin-eosin. The tumors were measured in number and the maximal diameter, and the number of satellite tumor nodules was counted. We also measured the distance between the tumor nodules and the main tumor. The 2010 TNM classification criterion was used to assign the tumors into their respective stages based on clinical and pathological findings [9]. Patient's first follow-up was 6 months after surgery, during which physical examination, routine blood work, serum chemistry tests, and abdominal US and chest imaging were conducted. Then CT scanning was performed in the 1st, 3rd, 5th year, and US was performed in the 2nd and 4th year. Elective bone scanning, or magnetic resonance imaging was employed when clinically indicated. Tumor recurrence, regional lymph nodes or distant metastasis was monitored. The death of individual was confirmed by death certificates alone, and the cause of death had to be RCC demonstrated on the death certificate to reduce bias of cause of death.

\section{Statistical analysis}

For statistical analysis, Pearson's Chi-square test and Fisher's exact test were performed to assess the association between categorical variables. The Kaplan-Meier method was performed to calculate survival functions. Two-sided $p$ value $<0.05$ was considered as statistical significance. All statistical analyses were performed using SPSS v.17.0 (SPSS Inc., Chicago, IL, USA) by one of the authors.

\section{Results}

A total of 600 individuals were recruited in the study, including 442 males and 158 females between the age of 29 and 73 (years), with a mean age of 58 years, 324 tumors in the right kidney and 276 in the left. Among them, 421 cases underwent NSS, and 179 cases underwent RN. For the 421 patients that underwent NSS, 42 received open approach and 379 received laparoscopic approach. During surgery, the renal artery was clamped for all of them. Of the 600 patients, 32 cases were multifocal, with 14 cases of clear cell tumors, 15 papillary tumors, 1 chromophobe tumor and 2 Xp.11.2 translocation RCC (Table 1). It was found that these tumors contain at least one smaller accompanying tumors around the primary tumor (Fig. 1), and some even had 8

Table 1 The clinical and pathological characteristics of 600 patients treated with NSS or RN for T1RCC

\begin{tabular}{llll}
\hline & Overall & Monofocal & Multifocal \\
\hline $\begin{array}{lll}\text { Age (years) } \\
\text { Range }\end{array}$ & & & \\
Mean & $29-73$ & $32-73$ & $29-73$ \\
Gender & 59 & 61 & 57 \\
Male & & & \\
Female & 442 & 419 & 23 \\
Laterality & 158 & 149 & 9 \\
Right & & & \\
Left & 324 & 304 & 20 \\
Type of surgery & 276 & 258 & 18 \\
NSS & & & \\
RN & 421 & 400 & 21 \\
Histological sub-type (NSS/RN) & 168 & 11 \\
Clear cell & $469(326 / 143)$ & $455(319 / 136)$ & $14(7 / 7)$ \\
Papillary & $91(67 / 24)$ & $76(55 / 21)$ & $15(12 / 3)$ \\
Chromophobe & $31(26 / 5)$ & $30(25 / 5)$ & $1(1 / 0)$ \\
Xp.11.2 translocation & $9(2 / 7)$ & $7(1 / 6)$ & $2(1 / 1)$ \\
\hline
\end{tabular}

NSS nephron-sparing surgery, $R C C$ renal cell carcinoma 
Fig. 1 The gross examination for specimen of multifocal renal cell carcinoma. a Radical nephrectomy; b nephron-sparing surgery. c Primary tumor with 8 accompanying tumors. Red arrow: primary tumor; blue arrow: smaller tumor
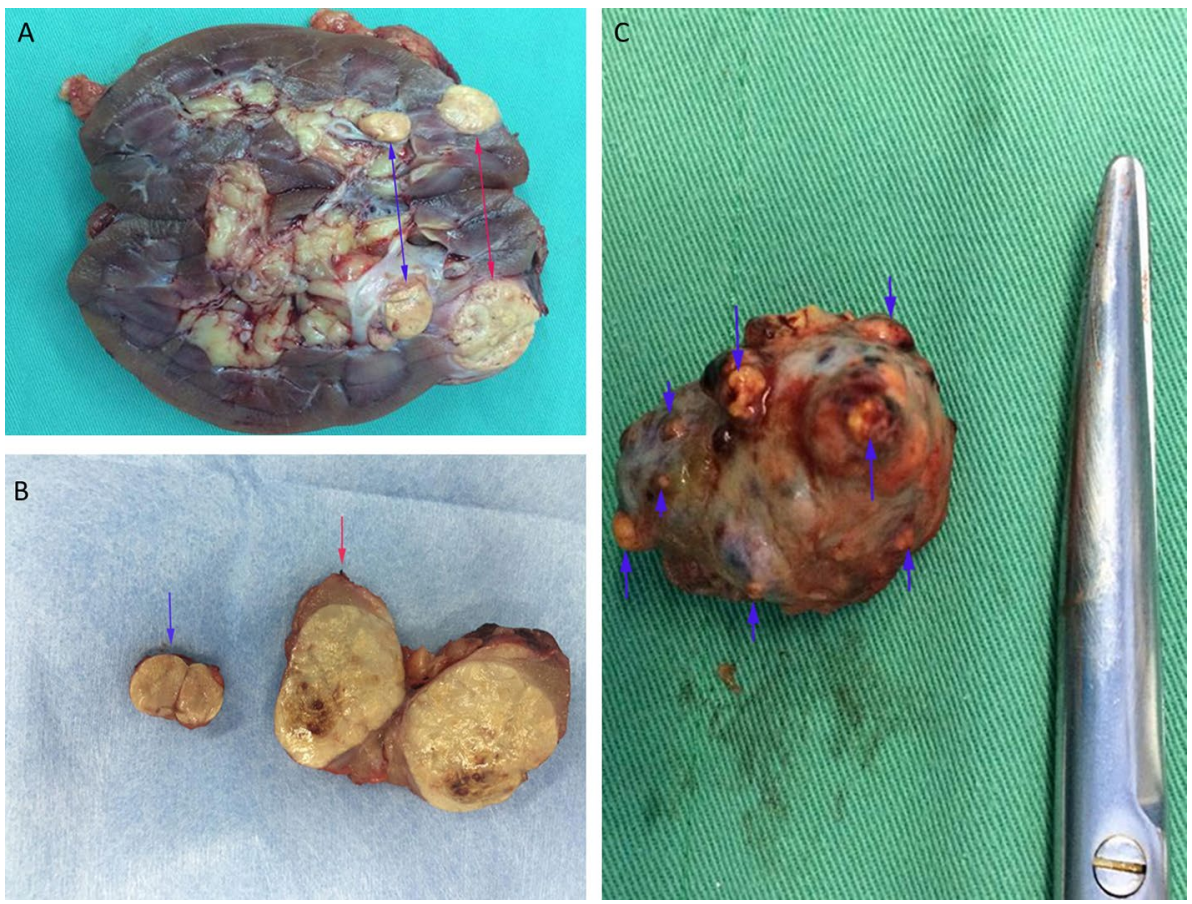

accompanying tumors according to the examination of gross pathological specimen (Fig. 1c). Based on the microscopic examination results, we found some primary tumors had at least one smaller accompanying tumor nodule, sometimes one (Fig. 2a), sometimes two (Fig. 2b), even three (Fig. 2c). However, occasionally, the accompanying tumors were similar with the primary tumor in size (Fig. 2d). All of the tumors were localized at the cortex. Out of the 32 cases, 11 had satellite tumor nodules with the number ranging from 1 to 4 and a mean pathological size of $3 \mathrm{~mm}$ (range $2-5 \mathrm{~mm}$ ). The mean distance from the predominate tumor was $2 \mathrm{~mm}$ (range 1-7 mm) (Table 2). The follow-up of the whole cohort was $45-80$ months (median $=60$ months). During the follow-up, there were 4 patients who had died of cancer ( 2 underwent NSS, remaining $2 \mathrm{RN}$ ) out of the 32 individuals with multifocal renal tumors $(p=0.48)$ (Fig. 3a). Out of the 421 patients who had undergone NSS, 13 of them presented with recurrence, 2 with multifocal renal tumors, and 11 with
Fig. 2 The microscopic examination for specimens of multifocal renal cell carcinoma. a Primary tumor and one accompanying tumor $(40 \times)$; b primary tumor and two accompanying tumors $(100 \times)$; c primary tumor and three accompanying tumors $(200 \times)$, $\mathbf{d}$ the primary tumor and the accompanying tumor are similar in size $(200 \times)$. Red arrow: primary tumor; blue arrow: accompanying tumor
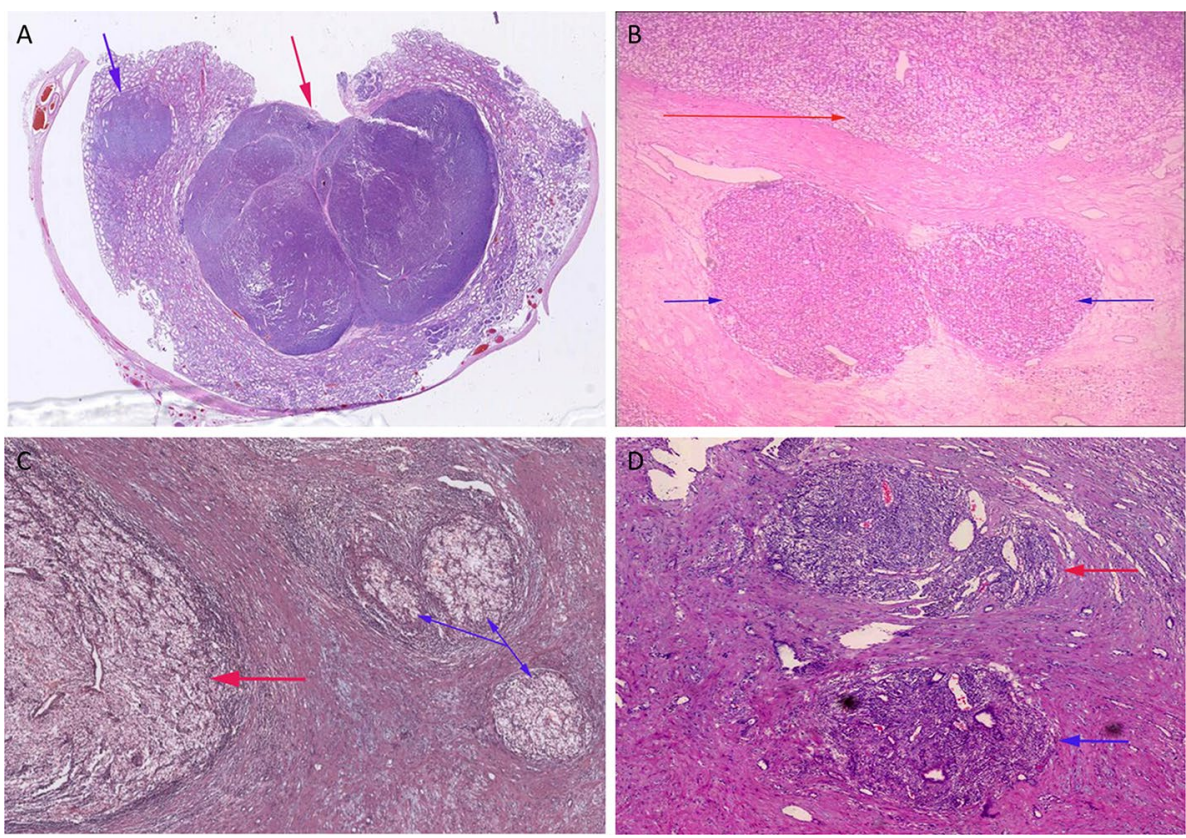
Table 2 The pathological characteristics of 11 patients with satellite tumour nodules in $32 \mathrm{~T} 1$ multifocal RCC patients

\begin{tabular}{llllll}
\hline $\begin{array}{l}\text { Speci- } \\
\text { men } \\
\text { number }\end{array}$ & $\begin{array}{l}\text { Primary tumor size } \\
(\mathrm{mm} \times \mathrm{mm} \times \mathrm{mm})\end{array}$ & $\begin{array}{l}\text { Number } \\
\text { of nod- } \\
\text { ules }\end{array}$ & Histological pattern & $\begin{array}{l}\text { Distance from } \\
\text { primary tumor } \\
(\mathrm{mm})\end{array}$ & $\begin{array}{l}\text { The maximum diam- } \\
\text { eter of nodules }(\mathrm{mm})\end{array}$ \\
\hline 1 & $32 \times 24 \times 22$ & 2 & Clear cell & 3 & 4 \\
2 & $27 \times 22 \times 21$ & 1 & Clear cell & 3 & 2 \\
3 & $45 \times 33 \times 30$ & 1 & Clear cell & 1 & 3 \\
4 & $32 \times 27 \times 22$ & 3 & Clear cell & 4 & 2 \\
5 & $36 \times 29 \times 25$ & 2 & Clear cell & 2 & 3 \\
6 & $33 \times 26 \times 23$ & 4 & Clear cell & 8 & 4 \\
7 & $30 \times 26 \times 24$ & 1 & Clear cell & 3 & 3 \\
8 & $35 \times 25 \times 24$ & 2 & Clear cell & 3 & 4 \\
9 & $31 \times 21 \times 21$ & 1 & Papillary & 2 & 5 \\
10 & $52 \times 28 \times 23$ & 2 & Papillary & 3 & 3 \\
11 & $27 \times 25 \times 24$ & 1 & Papillary & 3 & 2 \\
\hline
\end{tabular}

$R C C$ renal cell carcinoma
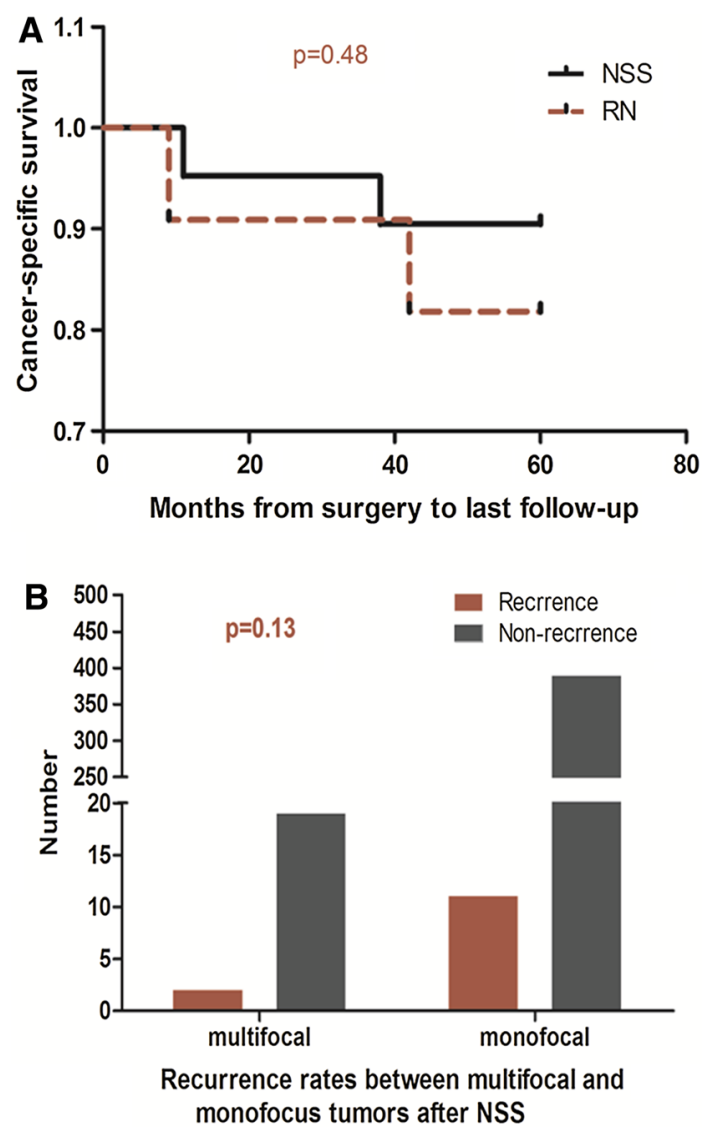

Fig. 3 a Cancer-specific survival in patients with T1 multifocal renal cell carcinoma undergoing nephron-sparing surgery versus radical nephrectomy $(p=0.48)$. b Recurrence rates of multifocal and monofocal tumors after nephron-sparing surgery $(p=0.13)$ monofocal renal tumors, respectively $(p=0.13)$ (Fig. 3b) and only in 1 patient, metastasis was observed.

\section{Discussion}

T1 RCC, limited to the kidney, is commonly defined as a neoplasm that presents with a diameter of less than $7 \mathrm{~cm}$ upon abdominal imaging. Multifocal tumors are particularly challenging to operate on, as there is at least one smaller tumor around the predominate tumor. Previously, RN was the primary therapeutic strategy for these individuals [10]. Owing to the rapid development of surgical techniques, NSS has been reported to be used for multifocal renal tumor in recent years, including robot-assisted NSS for sporadic ipsilateral multifocal renal tumors [11]. In general, there is variety of options for NSS, including open NSS, laparoscopic NSS, or even robot-assisted NSS. However, oncologic outcome of sporadic multifocal RCC treated with NSS was unsatisfactory. Due to the mulitfocality nature of the tumors, it is theoretically possible for residual tumors to still be present after the surgery. However, most studies have shown that NSS did not increase the rate of tumor recurrence, as well as cancer-specific survival [12-14]. Our study identified 21 patients with multifocal RCC who had undergone NSS presented with recurrence and 11 who had undergone RN. There was no significant statistical difference in the 5-year cancer-specific survival rate for NSS and RN, which was found to be $90.48 \%$ and $81.82 \%$, respectively ( $p=0.48$ ).

There were multiple findings associated with the satellite tumor nodules, including the inability of satellite tumor nodules to be detected by US or CT scanning preoperatively [5]. In addition, most satellite tumor nodules could not be identified by gross examination during operation as well. Therefore, the presence of satellite tumor nodules may be a 
risk factor for tumor recurrence on the basis of these findings. During clinical follow-up, there were few recurrence cases contradictory to our hypothesis. However, after measuring the distance from the primary tumor to satellite tumor nodules, we found that more than $80 \%$ of tumor nodules are within $4 \mathrm{~mm}$ from the primary tumor. The traditional suggestion of surgical marginal width was at least $1 \mathrm{~cm}$ of normal kidney tissue around the mass [15]. According to this standard, almost all the satellite tumor nodules will be removed during NSS. Later, some studies proposed that if the tumor was completely resected, the margin less than $5 \mathrm{~mm}$ around the tumor was also feasible for small renal mass by NSS [16]. However, due to the presence of satellite tumor nodules, a surgical marginal width of at least $1 \mathrm{~cm}$ of normal kidney tissue around the mass was found to be the most reasonable. The best surgical marginal width still needs further research.

Another indication of a minimally invasive approach for multifocal RCC was suggested in the present study. Out of the 420 patients who had undergone NSS, 13 had recurrence, 2 had multifocal RCC, and 11 had monofocal RCC. No significant difference was observed between them $(p=0.13)$. We also analyzed the positive surgical margin (PSM) that was important factors for tumor recurrence, and found 1 PSM for multifocal RCC, and 12 PSMs for monofocal RCC, respectively, considering the fact that the PSMs were rare, we did not calculate the $p$ value. It seemed that multifocal RCC has a higher rate of PSMs (3.13\% of multifocal RCC vs. $2.29 \%$ of monofocal RCC), which may be related to satellite tumor nodules. Since satellite tumor nodules could not be identified by gross examination during NSS, there was a high possibility of being incised during surgery. However, the recurrence of those cases was rare during clinical follow-up, which was thought to be related to one of the two reasons. First, surgeons typically used argon-beam coagulation in the NSS bed to achieve satisfactory renal parenchymal hemostasis after tumor resection, which also destroys potential cancer cells [17]. Second, T1 RCC commonly grows more slowly, especially for clear cell tumors and papillary tumors. Although the recurrence rate of multifocal RCC was low, surgeons still should pay attention to it, especially for the RCC with satellite tumor nodules. The location of some tumor nodules were distant from the primary tumor, and ectopic recurrence may occur after NSS. In our study, 2 cases out of 21 patients with multifocal RCC who had undergone NSS suffered from relapse, and both of them were ectopic recurrence. We hypothesized it may be related to satellite tumor nodules.

After the analysis of the histological pattern of multifocal RCC, we found papillary tumors accounted for the largest proportion (46.88\%), followed by clear cell tumors, and Xp.11.2 translocation RCC with 2 out of the 32 cases of multifocal RCC. Chromophobe tumors accounted for the least proportion, with only one case presented. This finding was different in comparison to some of the suggestions listed in previous studies. A previous study included 2569 patients with renal tumors, among whom 97 were identified with unilateral synchronous multifocal RCC, 87 with clear cell tumors and 59 with papillary tumors [18]. Another study also found similar results, with clear cell tumors having the highest proportion when compared to that of papillary tumors in multifocal RCC $(68.8 \%$ vs. $18.8 \%$ ) [19]. However, the two studies mentioned above did not distinguish the stage of RCC, whereas our study was only specific to T1 RCC, which might have resulted in the inconsistency with our findings, along with the sample size. Papillary tumor is the second most commonly occurring morphotype of RCC, and has a better prognosis than clear cell tumors [20]. Papillary tumors accounted for a high proportion of $\mathrm{T} 1$ multifocal $\mathrm{RCC}$ and might be associated with the good prognosis after NSS. However, we also found 2 cases of Xp.11.2 translocation RCC in this cohort, 1 of them recurred in 10 months after NSS. Xp11.2 translocation RCC is a biologically aggressive RCC with an unfavorable prognosis, which is more common in females under the age of 40 years, and men older than 50 may have the worst prognosis [21]. Distant metastasis and node metastasis often occur after surgery of NSS for Xp11.2 translocation RCC. Targeted therapy did not have obvious efficacy for this patient [22]. To avoid this clinical outcome, surveillance after NSS is extremely important.

Based on observations and evaluations made during the study, due to the low incidence of T1 multifocal RCC and the highest proportion of papillary RCC, which has a better prognosis, we recommend a minimally invasive approach such as laparoscopic NSS for T1 multifocal RCC. The presence of satellite tumor nodules may be a risk factor contributing to ectopic recurrence. T1 Xp11.2 translocation RCC requires thorough surveillance after NSS to obtain the more satisfactory prognosis.

Although our study provided an insight on the therapeutic option most effective in the treatment of T1 multifocal RCC, there were some limitations to it. First, since this was a retrospective multi-center study, inclusion criteria and surgical resection range were difficult for standardization, thereby it may have caused several potential biases. Second, the best way to examine the multifocal tumors is to perform a complete pathological examination for tissue sections after radical resection of the kidney. Since there were no large tissue sections studied in this group, the multifocality ratio may be lower than the actual situation, due to the low incidence of T1 multifocal RCC. Third, the relatively small sample sizes may lead to a higher heterogeneity of the research. Finally, our follow-up time may be short. 


\section{Conclusion}

Taken together, in multifocal renal tumors, papillary carcinoma may be more commonly occurring than clear cell carcinoma according to the pathological examination findings. The recurrence rate and survival rate of multifocal RCC were similar to monofocal tumors after surgeries. Tumor recurrence may be related to satellite tumor nodules that cannot be detected before surgery.

Funding This work was supported by the National Natural Science Foundation of China (Grants 81472682 and 81772756), and the Natural Science Foundation of Tianjin (17JCZDJC35300, 15JCZDJC35400 and 15JCYBJC27200), and the Tianjin Municipal Natural Science Foundation (Grant 17JCYBJC26000)

\section{Compliance with ethical standards}

Conflict of interest The authors declare that they have no conflicts of interest.

Ethical approval This research was approved by the Ethical Committee Review Board of the Second Hospital of Tianjin Medical University, Tianjin, China, and has been performed according to the ethical standards of Declaration of Helsinki.

Informed consent All the participants provided written informed consents.

Open Access This article is distributed under the terms of the Creative Commons Attribution 4.0 International License (http://creativecommons.org/licenses/by/4.0/), which permits unrestricted use, distribution, and reproduction in any medium, provided you give appropriate credit to the original author(s) and the source, provide a link to the Creative Commons license, and indicate if changes were made.

\section{References}

1. Beaugerie A, Audenet F, Verkarre V, Delavaud C, Le Guilchet T, Hurel S, de Saint Aubert N, Correas JM, Fontaine E, Richard S, et al. Pathological heterogeneity in sporadic synchronous renal tumors: is the histological concordance predictable? Urol Oncol. 2018;36(1):11.e17-11.e12.

2. Kane CJ, Mallin K, Ritchey J, Cooperberg MR, Carroll PR. Renal cell cancer stage migration: analysis of the National Cancer Data Base. Cancer. 2008;113(1):78-83.

3. Baltaci S, Orhan D, Soyupek S, Beduk Y, Tulunay O, Gogus O. Influence of tumor stage, size, grade, vascular involvement, histological cell type and histological pattern on multifocality of renal cell carcinoma. J Urol. 2000;164(1):36-9.

4. Li Q, Guan H, Zhang Q, Xue J, Wang F, Song X. Multicentricity and its associated factors in renal cell carcinoma. Chin Med J. 2002;115(9):1341-4.

5. Melissourgos N, Doumas K, Messini I, Papaliodi E, Kastrinakis NG, Lykourinas M. Multicentricity in renal cell carcinoma: can primary tumor location serve as a co-determinant of surgical treatment? Eur Urol. 2002;41(3):262-6.

6. Dimarco DS, Lohse CM, Zincke H, Cheville JC, Blute ML. Longterm survival of patients with unilateral sporadic multifocal renal cell carcinoma according to histologic subtype compared with patients with solitary tumors after radical nephrectomy. Urology. 2004;64(3):462-7.

7. Richstone L, Scherr DS, Reuter VR, Snyder ME, Rabbani F, Kat$\tan$ MW, Russo P. Multifocal renal cortical tumors: frequency, associated clinicopathological features and impact on survival. J Urol. 2004;171(2 Pt 1):615-20.

8. Fergany AF, Hafez KS, Novick AC. Long-term results of nephron sparing surgery for localized renal cell carcinoma: 10-year followup. J Urol. 2000;163(2):442-5.

9. Edge SB, Compton CC. The American Joint Committee on Cancer: the 7th edition of the AJCC cancer staging manual and the future of TNM. Ann Surg Oncol. 2010;17(6):1471-4.

10. Baiocco JA, Metwalli AR. Multiplex partial nephrectomy, repeat partial nephrectomy, and salvage partial nephrectomy remain the primary treatment in multifocal and hereditary kidney cancer. Front Oncol. 2017;7:244

11. Hankins RA, Walton-Diaz A, Truong H, Shih J, Bratslavsky G, Pinto PA, Marston Linehan W, Metwalli AR. Renal functional outcomes after robotic multiplex partial nephrectomy: the National Cancer Institute experience with robotic partial nephrectomy for 3 or more tumors in a single kidney. Int Urol Nephrol. 2016;48(11):1817-21.

12. Krambeck A, Iwaszko M, Leibovich B, Cheville J, Frank I, Blute M. Long-term outcome of multiple ipsilateral renal tumours found at the time of planned nephron-sparing surgery. BJU Int. 2008;101(11):1375-9.

13. Siracusano S, Novara G, Antonelli A, Artibani W, Bertini R, Carini M, Carmignani G, Ciciliato S, Cunico SC, Lampropoulou $\mathrm{N}$, et al. Prognostic role of tumour multifocality in renal cell carcinoma. BJU Int. 2012;110(11 Pt:B):E443-8.

14. Mano R, Kent M, Larish Y, Winer AG, Chevinsky MS, Hakimi AA, Sternberg IA, Sjoberg DD, Russo P. Partial and radical nephrectomy for unilateral synchronous multifocal renal cortical tumors. Urology. 2015;85(6):1404-10.

15. Uzzo RG, Novick AC. Nephron sparing surgery for renal tumors: indications, techniques and outcomes. J Urol. 2001;166(1):6-18.

16. Li QL, Cheng L, Guan HW, Zhang Y, Wang FP, Song XS. Safety and efficacy of mini-margin nephron-sparing surgery for renal cell carcinoma 4-cm or less. Urology. 2008;71(5):924-7.

17. Eggener $\mathrm{S}$. Editorial comment on: positive surgical margin appears to have negligible impact on survival of renal cell carcinomas treated by nephron-sparing surgery. Eur Urol. 2010;57(3):472.

18. Simhan J, Canter DJ, Sterious SN, Smaldone MC, Tsai KJ, Li T, Viterbo R, Chen DY, Greenberg RE, Kutikov A, et al. Pathological concordance and surgical outcomes of sporadic synchronous unilateral multifocal renal masses treated with partial nephrectomy. J Urol. 2013;189(1):43-7.

19. Sargin SY, Ekmekcioglu O, Arpali E, Altinel M, Voyvoda B. Multifocality incidence and accompanying clinicopathological factors in renal cell carcinoma. Urol Int. 2009;82(3):324-9.

20. Moch H, Cubilla AL, Humphrey PA, Reuter VE, Ulbright TM. The 2016 WHO classification of tumours of the urinary system and male genital organs-part A: renal, penile, and testicular tumours. Eur Urol. 2016;70(1):93-105.

21. Hora M, Urge T, Travnicek I, Ferda J, Chudacek Z, Vanecek T, Michal M, Petersson F, Kuroda N. Hes O: miT translocation renal cell carcinomas: two subgroups of tumours with translocations involving $6 \mathrm{p} 21[\mathrm{t}(6 ; 11)]$ and $\mathrm{Xp} 11.2[\mathrm{t}(\mathrm{X} ; 1$ or $\mathrm{X}$ or 17$)]$. SpringerPlus. 2014;3:245

22. Lim B, You D, Jeong IG, Kwon T, Hong S, Song C, Cho YM, Hong B, Hong JH, Ahn H. Clinicopathological features of Xp11.2 translocation renal cell carcinoma. Korean J Urol. 2015;56(3):212-7. 